González Castro, Antonio María.

Alumno vinculado a un grupo de investigación de la Universidad de Sevilla.

Sáez Pradas, Fernando.

Personal Investigador Dpto Dibujo. Universidad de Sevilla.

\title{
Autoconsciencia temporal: On Kawara y las redes sociales.
}

\author{
TIPO DE TRABAJO \\ Comunicación virtual. \\ PALABRAS CLAVE \\ On Kawara, redes sociales, autoconsciencia, artificio, temporalidad.
}

KEY WORDS

On Kawara, Social networks, consciousness, artifice, temporality.

\section{RESUMEN}

El transcurso de la postmodernidad supuso, tanto para el arte como para la sociedad, unas transformaciones fugaces y vertiginosas. La necesidad de actualizarse y encauzar con valentía los acontecimientos modernos conllevó una reflexión sobre las nuevas individualidades y sus condiciones identitarias. Los antiguos absolutos se relativizaron, y con ellos la forma de entender y valorar el tiempo. La contemporaneidad ha permitido enfocar esta cuestión desde un punto de vista nuevo, menos universal y vaporoso, y más concreto y manejable. Se entiende que la reflexión principal no reside en concebir el tiempo como una realidad elemental, sino en la interpretación personal que se hace de él, en el artificiovirtualidad que cada persona construye para sentir su presencia. El paso del tiempo es algo inevitable con lo que debemos lidiar, pero hay diferentes maneras de hacerlo y esto lo comprendió muy bien el artista On Kawara (1933-2014). Desde el ámbito de lo privado y lo íntimo, el tiempo deja de ser un valor absoluto y se convierte en una percepción individualizada que depende del artista y de su conciencia de "estar en el mundo". Lo real frente a lo artificioso, el tiempo histórico frente al tiempo relativo. Es significativo analizar cómo esto no ha pasado de moda y cómo los adolescentes actuales no dudan en publicar constantemente el transcurrir de su día a día en plataformas web o redes sociales. El sujeto comienza a hablar en un espacio virtual donde aparentemente defiende su autonomía, con una ignorancia personal que parece resolverse con una suerte de inteligencia despersonalizada. A través de obsesivas anotaciones acerca de su lugar en el mundo, el afán que muestran por defender la autoconsciencia tanto el artista como los adolescentes no es más que la autoafirmación de que existen realmente. Pero ¿qué diferencias encontramos entre ellos?

\section{ABSTRACT}

Postmodernism meant for both art and society a fugitive and vertiginous transformations. The need to upgrade and channel boldly modern events led to a reflection on the new individuality and identity conditions. They relativized the old absolutes, and with them the way we understand and appreciate the time. It has allowed contemporary approach this issue from a new, less universal, flowing, and more concrete and manageable view. It is understood that the main reflection is not in conceiving time as an elementary reality, but in the personal interpretation that makes him, in the device-virtuality that each person constructs to feel his presence. The passage of time is inevitable that we have to deal with, but there are different ways to do it and that he understood very well the artist On Kawara (1933-2014). From the realm of the private and intimate, time it ceases to be an absolute value and becomes individualized perception depends on the artist and his awareness of "being in the world". The real against the artificial, historical time versus relative time. It is significant to analyze how this has not gone out of fashion and how today's teenagers do not hesitate to consistently post the passing of their day to day web platforms and social networks. The subject begins to speak in a virtual space where apparently defends its autonomy, with personal ignorance that seems resolved with a kind of impersonal intelligence. Through obsessive notes on their place in the world, the desire to defend the self-consciousness shown by both the artist and teens is nothing more than the affirmation that actually exist. But what are differences between them? 


\section{CONTENIDO}

Introducción

Hacia finales de los años cincuenta, el sentimiento general que se percibe tras las dos guerras es de una absoluta desconfianza en el sistema establecido. La estupidez humana había culminado en las más sanguinarias atrocidades de toda la historia de la humanidad. Si el proyecto moderno, basado en la razón y la ciencia, había llevado al hombre al caos y a la destrucción, ya no tenía sentido seguir creyendo en él. Como consecuencia, gran parte de la actividad intelectual de mediados de siglo XX se congregó en torno a la defensa del pensamiento existencialista, entendiendo que la evolución moral del ser humano arranca desde el conocimiento íntimo y la acción individual sin tener nada que ver con todos aquellos argumentos y moralinas sobreimpuestas desde el exterior. Los artistas de todas las ramas comenzaron a incubar un pensamiento revolucionario que pretendía subvertir el orden establecido, donde lo importante era cuestionar el papel que tenía el arte respecto a todo lo que estaba sucediendo a su alrededor. Es así como se consolidó un importante dominio conceptual fundamentado en la autorreflexión del arte y del artista sobre sí mismo: quién soy yo, qué sentido tiene la vida para mi y qué función tengo en el contexto en el que me inserto.

La filosofía que desarrollaron autores como Jean-Paul Sastre proporcionó argumentos en torno a una ética válida para todos los seres humanos, universal a nuestra especie e independiente de sus culturas y creencias. Ya no se entendían como propios los valores "del otro", ni del colectivo, sino que comienza a esbozarse un periodo en el que se disuelven todo tipo de narraciones totalizadoras de asuntos como la raza, el estado, la nación o la política. La actitud en la vida real construye la propia esencia del ser humano y sus actos determinan el sentido de su "estar en el mundo". El proceso entonces se invierte: ya no es la sociedad quien dictamina unos valores que deben ser recogidos por el resto de individuos; ahora emergen desde lo individual para ser comunicados $y$ compartidos, y entonces actuar desde lo colectivo.

\section{La duda y la sospecha como impulso}

En esta búsqueda de nuevas direcciones es donde aparece un sentimiento de desconfianza hacia las disciplinas artísticas. Se inicia en las artes un proceso de cuestionamiento de los métodos tradicionales que empiezan a poner en duda la capacidad significativa de las imágenes. "Desconfianza e inquietud que ha llevado al arte a una permanente actitud autorreflexiva y de búsqueda más allá del mundo de lo visual ${ }^{1}$. Envueltos en una filosofía del escepticismo, estos artistas renuncian a cualquier deidad o verdad universal para adentrarse en las profundidades de su propio ser, de sus propias contradicciones y juicios de valores. La devoción por el héroe y sus hazañas épicas resulta descerebrado para un artista que debe vivir discretamente como ciudadano, al servicio de sus propios conflictos. De este modo, la duda permanente hacia aquello que construye nuestro entorno fue una práctica habitual en artistas de la segunda mitad de siglo como el japonés On Kawara (1933-2014).

La fascinación y el enigma por las imágenes han estado siempre presentes en el arte a través de la actividad pictórica, sin embargo estas sospechas han constituido (y constituyen) una forma de relacionarnos con el mundo, sobre todo desde el auge de las nuevas tecnologías y los medios de comunicación. Como bien dice Jose Luis Molinuevo, "ya no se trata de creer en aquello que no saca de dudas sino en aquello que nos confirma en ellas" ${ }^{\prime 2}$. Esta ha sido una de las herencias claves recibida por nuestra sociedad contemporánea.

Acontecimientos tan importantes como los no muy lejanos atentados del 11-S nos llevaron a interpretar de una forma diferente las imágenes que aparecían en los medios, no sólo por la aparente irrealidad del acontecimiento sino porque reavivó el debate de sus posibles connotaciones políticas, sociales y económicas. Todo esto respaldado dos años antes por el rodaje de películas como "El show de Truman" o "Matrix", por noticias tan abrumadoras como las que apareció en el año 1996 de una aparente oveja común llamada Dolly que había sido el resultado de la primera clonación mamífera, o el estreno del primer reality-show holandés "Big-Brother"(Gran Hermano en España). Comienza entonces a elaborarse desde la actividad mediática un prototipo de "lo que debe ser", descendiente directo de aquellas propagandas pop que marcaban el nuevo estilo de vida americano (American Way of Life): el sueño de un sistema ideal con grandes promesas de futuro, con un potente aparato espectacular que evitaba mostrar la mugre del sistema. Se construye un artificio social externo a nosotros que empiezan a inculcarnos, con un lenguaje visual sutil pero no menos pernicioso, cómo debemos ser, qué tipo de ropa vestir y cuáles deben ser nuestros comportamientos para imitar a las estrellas que salen por televisión. Un "modus operandi" estereotipado, endogámico y súbdito de las demandas de un mercado amoral que no tiene escrúpulos en ofrecer todo aquello que sea morboso para el público.

Comenzamos por tanto a ser partícipes de un mundo que lo mercantiliza todo, donde el propio mercado está completamente desregulado, en el que a todos se nos exige incesantemente estar al $200 \%$ de nuestras capacidades para sobrevivir. Caemos en el foso del inmovilismo porque no encontramos soluciones colectivas, porque nos obligan permanentemente a darlo todo

\footnotetext{
${ }^{1}$ López Martínez, M. (2001). El cerco del sentido. En J. y. Agúndez García, Simposio Happening, Fluxus y otros comportamientos artísticos en la segunda mitad del siglo XX. Ponencias y Comunicaciones. Mérida: Editora Regional de Extremadura. Pg 195

${ }^{2}$ Molinuevo, J. L. (2003). Entre la tecnoloilustración y el tecnoromanticismo. En D. Hernández Sánchez, Arte, cuerpo, tecnología (pág. 290). Salamanca: Ediciones Universidad Salamanca. Pg 69
} 
de nosotros mismos, a estar felices para siempre, a no tener derecho a una simple y humana depresión. "Es el terrorismo contemporáneo de las sociedades neoliberales, con esa tendencia a la auto-supresión y a la soledad digital, que ha empezado a multiplicar la excitabilidad nerviosa y a encerrar a los cuerpos en la jaula de la pantalla. Es el capitalismo financiero que ha comenzado a forzarnos a todos a trabajar por más y más tiempo, bajo el miserable salario de la precariedad"”.

Y como no llegamos a ser los "triunfadores" que salen en pantalla, nos frustramos y paliamos nuestras penas comprando y buscando soluciones efímeras a problemas duraderos. Cada uno intenta buscar resultados individualizados; de aquí el auge de los libros de autoayuda y la necesidad por ser vitoreado constantemente por todo lo que haces en las redes sociales.

\section{La estrategia de On Kawara}

Dentro de los clasificados "Date paintings" de On Kawara encontramos una serie bastante particular llamada "Today". Son pinturas realizadas a mano con una fuente tipográfica sencilla en las que sólo aparece la fecha en las que han sido pintadas, centradas en el formato y muy habitualmente con una abreviación del mes correspondiente. Es preciso recordar que los periódicos fueron la fuente principal de información sobre la guerra de Vietnam, situación con la cual sentía una enorme complicidad. Estas pinturas en acrílico sobre lienzo pretensado, abarcan unas dimensiones entre los 20,5 x 25,5 cm y $155 \times 226 \mathrm{~cm}$ con unos bastidores de madera de unos $5 \mathrm{~cm}$ de grosor. Cuatro capas de pintura son aplicadas cuidadosamente desde la base con tiempo suficiente para el secado, seguidas de un frotado de preparación para las capas siguientes. El contorno de las letras es cuidadosamente dibujado con pintura blanca y diferentes instrumentos de precisión, invirtiendo una considerable cantidad de tiempo para limpiar imperfecciones y ajustar meticulosamente la composición final. Si la pintura no se termina antes de la medianoche del mismo día en que se hizo, será destruida.

El factor determinante de esta serie es que los lienzos son envueltos en unas cajas de cartón realizadas a mano con recortes de periódicos de ese mismo día. La coexistencia de las pinturas y las noticias nos suscita una percepción conmovedora: la obra artística no consigue nunca desvincularse del contexto en el que se inserta. Ambas se refieren al mismo día, son artefactos culturales. Sin embargo, el primero es único, básicamente hecho a mano, haciendo una declaración de intenciones sobre su presencia en el mundo. Su carácter artístico le concede una especie de atemporalidad constante, igual que pasaba con las pinturas de las cuevas prehistóricas, mientras que "el segundo es obviamente un producto mecánico, un papel que al día siguiente será caduco y probablemente se use como envoltorio de los "fish \& ships"4.

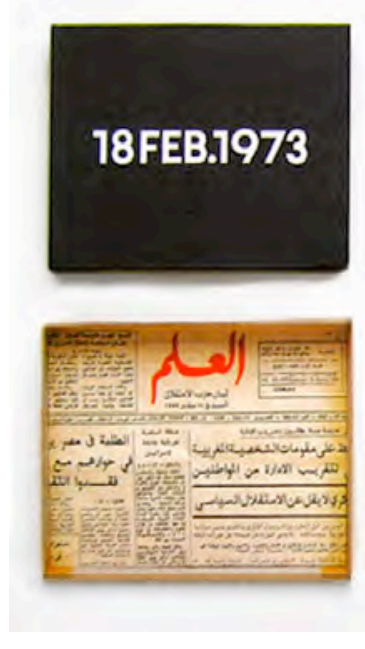

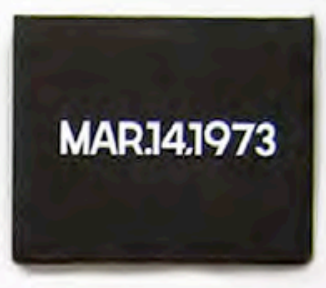
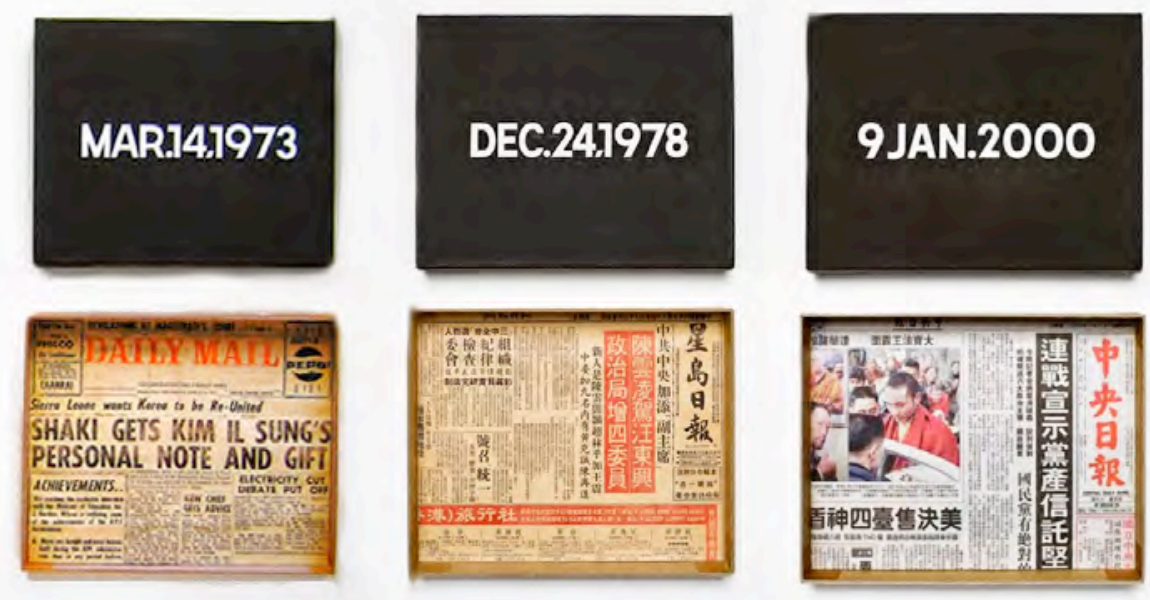

llustración 1. On Kawara. Serie "Today". Date painting

Estas ideas y cuestionamientos desencadenaron una tremenda obsesión por lo conceptual que llevó a reducir al máximo la materialidad de la obra por considerarla una distracción que nos aleja de lo fundamental. Este modo medieval de concebir el arte, que suprime canales expresivos para remitirse a lo esencial, ayuda a Kawara a desarrollar una estética basada en el relativismo con un intercambio de ideas que motivan un significado ontológico. Esto le vincula con toda esa generación de artistas que han asumido la teoría de la relatividad y que defienden la suposición de que la comprensión del tiempo es una cuestión completamente distorsionada e individualizada. Se suscribe al axioma por el cual el orden temporal de las cosas es un artificio humano (virtualidad) que sirve para

\footnotetext{
${ }^{3}$ Franco Berardi, B. (31 de Marzo de 2015). Eldiario.es. Obtenido de

http://www.eldiario.es/interferencias/Andreas_Lubitz_6_372422775.html

${ }^{4}$ Watkins, J. y. (2002). On Kawara. Londres: Phaidon. Pg 78
} 
comprender como nuestra percepción está más alejada del conocimiento y más próxima a la consciencia corpórea. A la misma vez que nos ofrece esos recortes de prensa con un contexto histórico paralelo a su obra, con los que poder ampliar los posibles significados artísticos, nos induce también a una especie de revelación en la que no existe ninguna verdad universal más allá de nuestra propia presencia en el mundo. El artificio del arte, y por tanto su carácter virtual, se convierte en un signo de supervivencia, en un testimonio de la existencia en un lugar y tiempo determinado. Es la comprensión de un periodo que mañana será pasado, responsable de unas determinadas secuelas en el futuro.

On Kawara se identifica con la ritualización del proceso artístico que llevaron a cabo aquellos hacedores de imágenes de las grutas de Altamira, cuevas a las que visitó y que produjeron un enorme impacto en su carrera artística. El rito y la serialidad de su trabajo funcionan como catalizadores para la experiencia de un tiempo personalizado, extendido y pormenorizado. Es una forma de meditación, de rutina que le conduce a librarse del ego y de todas esas distracciones que nos apartan de la verdad fundamental que compartimos con nuestros ancestros: la presencia en el mundo. En un contexto donde todo va tan rápido, hace falta pararse un poco, detenerse en el placer de lo íntimo, relativizando el tiempo a través de una actividad disciplinaria. "Los procedimientos de creación artística fundados en la serialidad fueron prácticamente ubicuos en la producción de los años sesenta. A través de ella los artistas de los años sesenta habrían proyectado la percepción de sí mismos y de su relación con el mundo, evidenciado cualidades como metodicidad y coherencia, y sentimientos como alienación" ${ }^{\prime 5}$.

\section{Acercándonos al presente en forma de conclusiones}

Es significativo percatar esa urgencia irrefrenable que tienen los adolescentes actuales por realizar obsesivas anotaciones acerca de su lugar en el mundo. Tal y como hizo Kawara, no dudan en publicar constantemente el transcurrir de su día a día en plataformas web o redes sociales. Atendiendo a esta comparación, es curioso descubrir que esta necesidad no ha pasado de moda. Sin embargo, encontramos enormes diferencias entre el contexto post-bélico que integra la obra de On Kawara y la virtualidad tecnológica de nuestros medios contemporáneos. Acercándonos más a nuestro ámbito actual descubrimos que la actividad que realizamos en estos canales no está teniendo una equivalencia del todo práctica en nuestra vida real. Quizás no deba tenerla, pero la cuestión reside en que tampoco ayudan a solucionar los problemas de nuestras comunidades.

La diferencia principal reside, no sólo en la separación temporal relativa a los dos periodos históricos, sino también en la voluntad y dificultad para diagnosticar esos problemas. Es decir, nuestro artista en cuestión comprende dónde está el origen de sus conflictos y responde - actúa frente a ello en forma de autoprotección. No exige ninguna respuesta, no espera nada del mundo más que su propia capacidad de decidir sobre él. Como réplica a unos acontecimientos incomprensibles, se fabrica su propio artificio (la virtualidad de la obra artística), su propia mentira sagrada (como diría Alejandro Jodoroswky, esa mentira que nos ayuda y nos da ánimos). Por el contrario, la tecnorealidad ha supuesto para toda esa generación de jóvenes nacidos en el nuevo estado del bienestar una falsa ilusión de realidad que, lejos de solucionar los problemas particulares, les ha hecho presos de su propio artificio. Tanto el artista como los jóvenes mantienen una posición escéptica respecto a lo que ven a su alrededor, sin embargo Kawara tiene esperanza en que puede cambiar algo, y crea un artilugio propio para defenderse de las contradicciones del mundo (y de las suyas propias). Por el contrario, gran parte de los usuarios navegantes por las redes virtuales están dando por válido un sistema engañoso externo a ellos (les viene ya dado) que no les facilita pistas para salir de sus preocupaciones. Pueden compartir su ficción con el resto de usuarios, pueden participar dentro de las leyes de la red virtual, pero al fin y al cabo no es más que una solución analgésica, paliativa y temporal que no se corresponde con las soluciones de la vida real.

Deducimos pues una voluntad de saneamiento individual por parte de Kawara en detrimento de una dinámica de la desatención por parte de los tecnonavegantes: la consciencia frente a la inconsciencia. Esto nos recuerda a esos célebres comentarios de Jodoroswky como terapeuta y psicomago, donde los "pacientes no quieren curarse porque saben que esa enfermedad le revelará cosas profundas. No se llega a la base espiritual y profunda del problema porque no interesa saber de dónde viene el sufrimiento"6. De esta manera, el existencialismo que persigue la libertad individual y el descubrimiento de lo desconocido, ayuda a Kawara a luchar contra sus propios temores y conflictos. La mentira, por tanto, es necesaria y respetable, es tan verdad como nuestras verdades; es parte de nuestro mundo.

"A la gente le encanta que le informen de que está engañada respecto a sí misma, el mundo en el que vive y que le informen (los medios de información) que la sociedad misma de la información es un engaño [...] Puede decirse que las nuevas tecnologías de mercado cumplen eficazmente ese reencantamiento del mundo"”.

\footnotetext{
${ }^{5}$ Santorelli, M. (Diciembre de 2011). La máquina Kawara: secuelas de serialidad en el arte del siglo XXI. Obtenido de http://msantorelli.hotglue.me/

${ }^{6}$ Jodorowsky, A. (13 de Mayo de 2011). Youtube. Obtenido de Alejandro Jodorowsky- Entrevista en "El loco de la colina" Parte 1: https://www.youtube.com/watch?v=58P97_B1ryw

${ }^{7}$ Molinuevo, J. L. (2003). Entre la tecnoloilustración y el tecnoromanticismo. En D. Hernández Sánchez, Arte, cuerpo, tecnología (pág. 290). Salamanca: Ediciones Universidad Salamanca. Pg 30.
} 


\section{4 horas - is}

Buuuuueeenooooosssss diiiiiiiiiiiaaaassss!!!!! buuuuueeenooooosssss diiiiiiaaassss!!!!!!!!!

Hoy... "Seguir adelante, como hacen los ríos y la gente que ríe." Yo he decidido reir mucho y tu? ::)

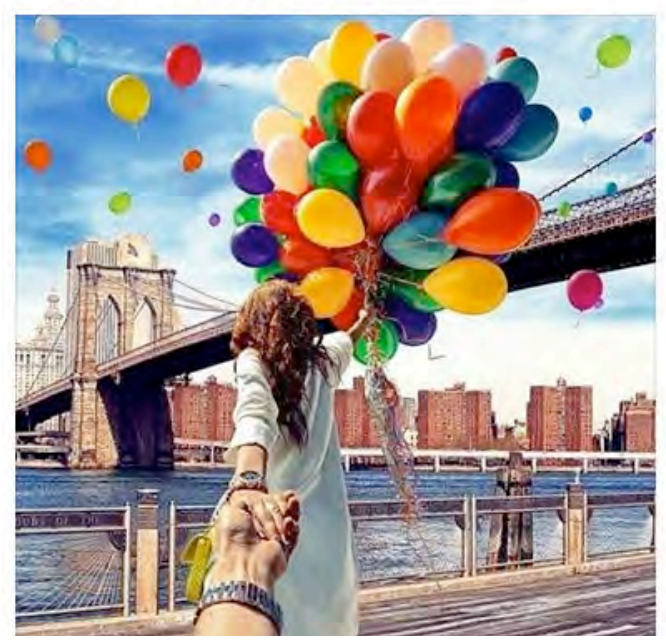

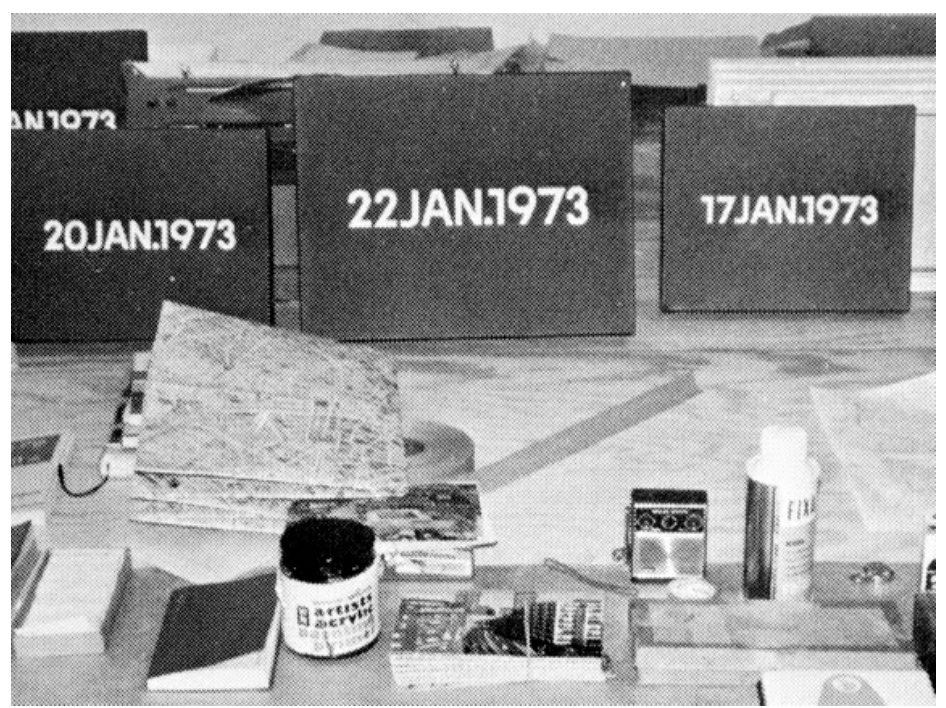

Ilustración 2. (Izq) Publicación en el muro de Facebook. 2014. (Dcha) On Kawara, Serie Today. Acrílico sobre lienzo. 1973

Lo que se espera en esos medios virtuales es esa confirmación comunitaria de las sospechas, donde aparentemente el sujeto habla y defiende su autonomía "con una ignorancia personal que parece resolverse con una suerte de inteligencia colectiva y despersonalizada ${ }^{8 \prime}$. Todo esto se relaciona con la recuperación tradicional de lo que Juan Carlos Monedero considera el fundamento del pensamiento crítico: "diagnosticar el problema para saber de dónde viene nuestro dolor". Esclarecer nuestros conflictos internos nos sirve, en primer lugar, para poder cambiarlos, y en segundo, para aplicar el conocimiento sobre ellos.

La dificultad de lidiar plenamente con los conflictos personales es un asunto que la filosofía existencialista trata de suscitar. Precisamente, fue el contexto post-bélico quien fomentó un clima de reflexión frente a un mundo que se había vuelto autodestructor y absurdo. La defensa del ser humano como un individuo libre y la capacidad de responsabilizarnos de nuestros propios actos no solamente conducen a un ambiente de autoescucha y de diálogos internos, sino de acción e interactividad con el mundo. "La realidad es algo más que discurso, que habla. Vivir es actuar, no solo opinar. La autonomía personal no se constituye con un sujeto que habla en un mundo virtual, sino con un sujeto real, valiente y sabio que actúa en el mundo real ${ }^{\prime 10}$. Este discurso sobre la realidad virtual y la vida real pasa inexorablemente por la autoidentificación del cuerpo, determinante a la hora de comprender las carencias, fantasías y deseos de cada individuo. Aquí encaja muy bien la pregunta de ¿puede la realidad virtual remplazar a la vida real? "Solo en la medida en que el teatro logre remplazar a la vida actual [...] Solo son dispositivos para mejorar la experiencia, completarla y distraernos de los contextos de la vida real ${ }^{\prime 11}$.

\footnotetext{
${ }^{8}$ Marina, J. A. (2004). Cronicas de la ultramodernidad. Barcelona: Quinteto. Pg 29

${ }^{9}$ Monedero, J. C. (01 de Junio de 2011). Juan Carlos Monedero - El gobierno de las palabras / The Government of Words. Obtenido de https://www.youtube.com/watch?v=9C-dJRp92wo

${ }^{10}$ Marina, J. A. (2004). Cronicas de la ultramodernidad. Barcelona: Quinteto. Pg 32

${ }^{11}$ Ihde, D. (2004). Los cuerpos en la tecnología. Nuevas tecnologías: nuevas ideas acerca de nuestro cuerpo. Barcelona: UOC. Pg 33
} 


\section{FUENTES REFERENCIALES}

Franco Berardi, B. (31 de Marzo de 2015). Eldiario.es. Obtenido de

http://www.eldiario.es/interferencias/Andreas_Lubitz_6_372422775.html

Fuentes Medrano, A. (2001). La dramaturgia de la danza contemporánea. Pamplona: Universidad de Pamplona.

Ihde, D. (2004). Los cuerpos en la tecnología. Nuevas tecnologías: nuevas ideas acerca de nuestro cuerpo. Barcelona: UOC.

Jodorowsky, A. (13 de Mayo de 2011). Youtube. Obtenido de Alejandro Jodorowsky- Entrevista en "El loco de la colina" Parte 1: https://www.youtube.com/watch?v=58P97_B1ryw

López Martínez, M. (2001). El cerco del sentido. En J. y. Agúndez García, Simposio Happening, Fluxus y otros comportamientos artísticos en la segunda mitad del siglo XX. Ponencias y Comunicaciones. Mérida: Editora Regional de Extremadura.

Marina, J. A. (2004). Cronicas de la ultramodernidad. Barcelona: Quinteto.

Molinuevo, J. L. (2003). Entre la tecnoloilustración y el tecnoromanticismo. En D. Hernández Sánchez, Arte, cuerpo, tecnología (pág. 290). Salamanca: Ediciones Universidad Salamanca.

Monedero, J. C. (01 de Junio de 2011). Juan Carlos Monedero - El gobierno de las palabras / The Government of Words. Obtenido de https://www.youtube.com/watch?v=9C-dJRp92wo

Santorelli, M. (Diciembre de 2011). La máquina Kawara: secuelas de serialidad en el arte del siglo XXI. Obtenido de http://msantorelli.hotglue.me/

Watkins, J. y. (2002). On Kawara. Londres: Phaidon. 